\title{
Some Effects of Hippocampal Lesions on the Behavior of Mongolian Gerbils'
}

\author{
STEPHEN E. GLICKMAN, ${ }^{2}$ THOMAS J. HIGGINS AND ROBERT L. ISAACSON ${ }^{3}$ \\ University of Michigan, Ann Arbor, Michigan, U.S.A.
}

(Received 3 February 1970)

\begin{abstract}
GLICKMAN, S. E., T. J. Higgins AND R. L. ISAACSON. Some effects of hippocampal lesions on the behavior of Mongoliangerbils. Physiol. BeHAv. 5 (8) 931-938, 1970.-Adult male gerbils (Meriones unguiculatus) were subjected to one of three surgical procedures: aspiration of the hippocampus and overlying cortex, aspiration of the cortex overlying the hippocampus alone, or a sham operation. Hippocampal lesions increased the frequency of certain home cage behavior patterns (locomotion, rearing, sniffing and drinking), decreased the frequency of other patterns (sleeping/lying and shredding of nest materials) and left unchanged a third set of measures (alert inactivity, grooming and burrowing). In those cases where increments in occurrence of a given behavior were observed, there were lesion-induced shifts in frequency of initiation of certain behavior patterns (locomotion and sniffing) rather than in the duration of those patterns. This finding argues against a simple perservation view of the increment in frequency of these patterns. Lesion effects on reactivity to novel stimulation varied with the test procedure. Locomotor activity in an open field was enhanced, manipulatory and biting contacts with novel stimulus objects were reduced, and social reactions to unfamiliar visitor gerbils were relatively unaffected.
\end{abstract}

Hippocampal lesions Gerbils Species-characteristic behavior patterns

HiPPOCAMPAL lesions in the rat produce a broad range of effects on locomotor exploration $[10,12,16,17,22]$, water intake [13], nest-building behavior [11] and such home-cage activities as locomoting, sniffing and sleeping [9]. However, in order to obtain a more complete profile of the behavioral modifications produced by hippocampal lesions, it seemed desirable to examine the diverse effects of such lesions within the confines of a single study. We accordingly decided to include the distribution of home cage behavior patterns, the response to visitor gerbils, the response to inanimate novel stimulus objects, and the locomotor exploration of a novel open field as response measures in the present study. Through the use of these measures and the selection of Mongolian gerbils (Meriones unguiculatus) as subjects, we hoped to accomplish three objectives. First, we were interested in the extent to which modifications in behavior sequences following hippocampal lesions could be attributed to perseverations of the particular activities or to changes in the frequency of initiating those activities. Second, we hoped to distinguish between possible differential effects of the lesions on behavior patterns emitted in a familiar environment and those emitted as a response to environmental change. Finally, it seemed appropriate to extend our analysis of hippocampal lesion effects to a rodent species other than the laboratory rat. The Mongolian gerbil, a small communally-dwelling desert rodent [21], has been the subject of a variety of psychological studies $[20,23]$. By virtue of the ubiquity and stereotypy of its nest-building [6], territorial [1, 23, 24] and social behavior patterns, the gerbil is a particularly attractive subject for the study of species-characteristic activities and their neural substrate.

\section{METHOD}

\section{Subjects}

Twenty-eight adult male gerbils, weighing between 70 and $90 \mathrm{~g}$, were originally designated as subjects in this experiment. Two animals died as the result of the surgical procedures and three animals were discarded when histological analysis revealed the presence of substantial infection at the site of the lesion. The remaining 23 gerbils were divided into three groups: a sham operate group $(\mathrm{N}=7)$, a cortical lesion group $(\mathbf{N}=7)$ and a hippocampal lesion group $(\mathbf{N}=9)$. All of these animals had been resident in their home cages for a minimum of three weeks prior to the initiation of the present experiment.

An additional group of 8 adult male and 8 adult female gerbils served as a pool from which visitors were randomly selected for tests of social interaction.

\section{Apparatus}

Test animals were individually housed in $12 \times 12 \times 24$ in. wooden boxes, with hinged hardware cloth lids and a front panel of clear glass. The boxes were covered to a depth of

'This research was supported by grants from the National Institute of Mental Health under the direction of S. E. Glickman (MH-13253) and R. L. Isaacson (MH-11285). The manuscript was prepared while the senior author was a fellow at the Center for Advanced Study in the Behavioral Sciences, Stanford, California, U.S.A.

2Present address: Department of Psychology, The University of California, Berkeley, California, U.S.A.

3Present address: Department of Psychology, The University of Florida, Gainesville, Florida, U.S.A. 
approximately $11 / 4 \mathrm{in}$. with medium grain aquarium gravel. A $600 \mathrm{ml}$ beaker was placed in a corner of the cage as a potential nest site and a metal drinking spout, attached to a $100 \mathrm{ml}$ graduated cylinder, protruded into the cage from one of the end walls. Visitor gerbils were housed in like-sexed groups of 4 within metal colony cages. Each day of the experiment, a $5 \times 8$ in. piece of cardboard was placed on the floor of the home cage of every gerbil. These pieces of cardboard served as a source of shreddable nesting material [6].

The open field was $3 \times 3 \mathrm{ft}$ and had wooden walls $1 \mathrm{ft}$ in height which were painted with a gray semi-gloss enamel. A sheet of white oilcloth, divided into 16,9 in. squares, served as the floor of the field. The field was illuminated by two $20 \mathrm{~W}$ fluorescent lamps mounted on the ceiling.

Novel objects employed in the curiosity test included $1 \frac{1}{2}$ in. lengths of 4 in. wooden dowel, 4 in. rubber tubing and stee! sash chain.

\section{Procedure}

Operative. Each animal was anesthetized with sodium pentobarbital, had a longitudinal incision made in the scalp and bilateral trephine holes drilled through the dorsal region of the skull posterior to bregma. The skin of the sham operate animals was sutured at this point and the animals returned to their cages for recovery. In the case of the remaining two groups, aspiration-produced lesions were made. These were either restricted to the dorsal neocortex overlying the hippocampus, or included both neocortex and as much of the underlying hippocampus as could be practically removed. These

H 1
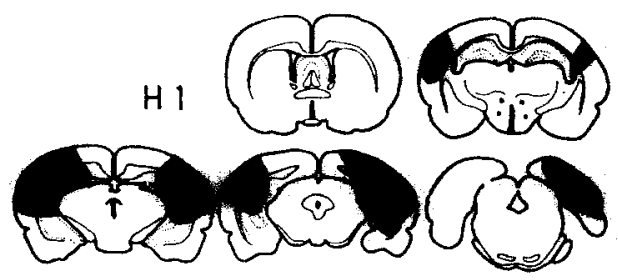

H3
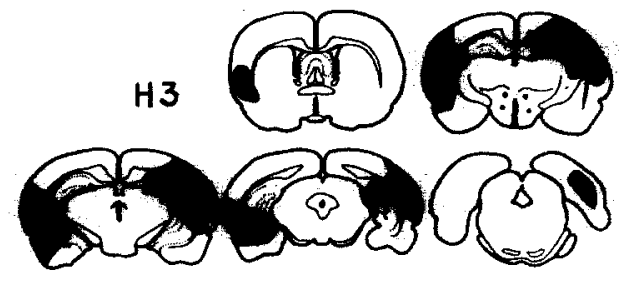

H6
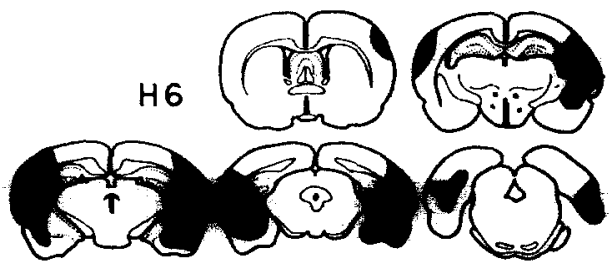

$\mathrm{H} 12$
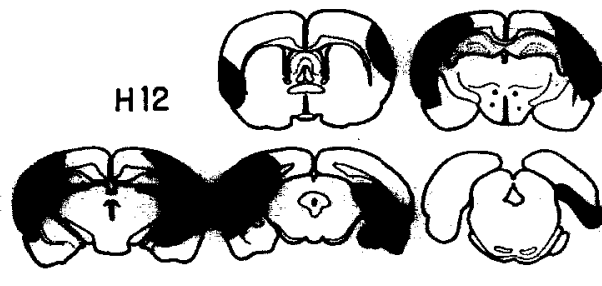

H 23

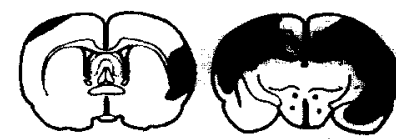

H 28
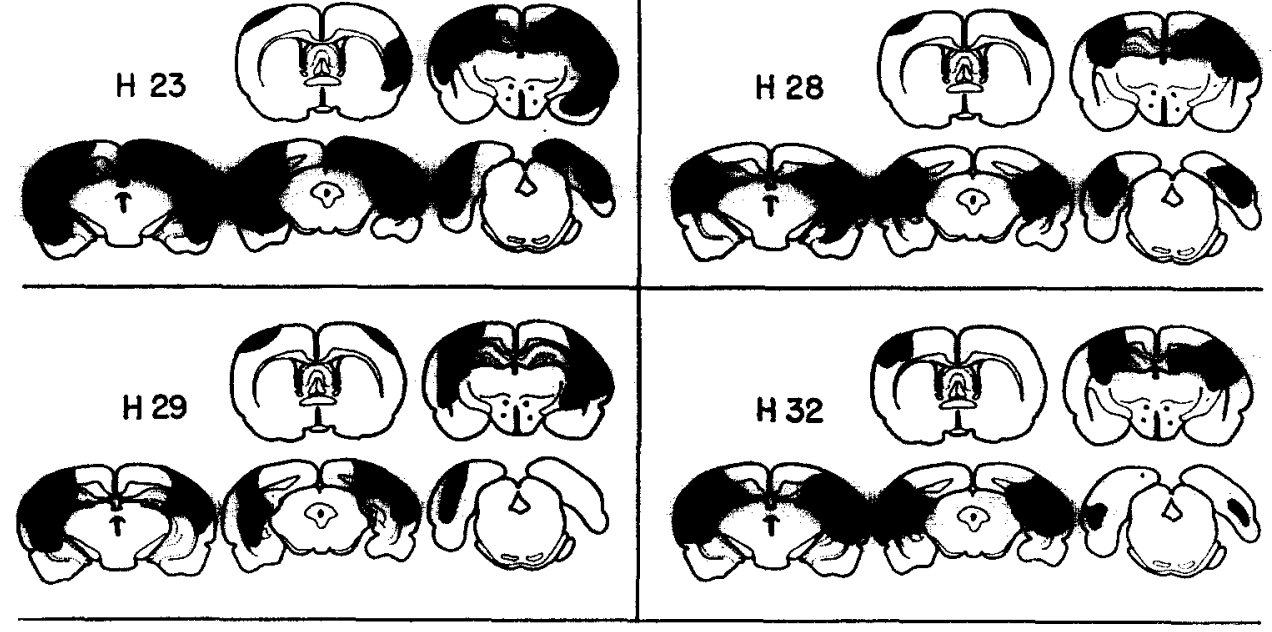

H 33
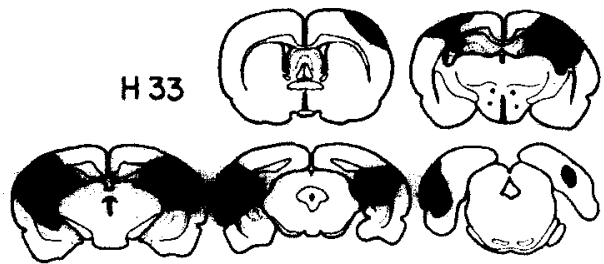

FIG. 1. Cross-sectional reconstructions of hippocampal lesions. Ablated tissue is indicated by solid dark areas. 


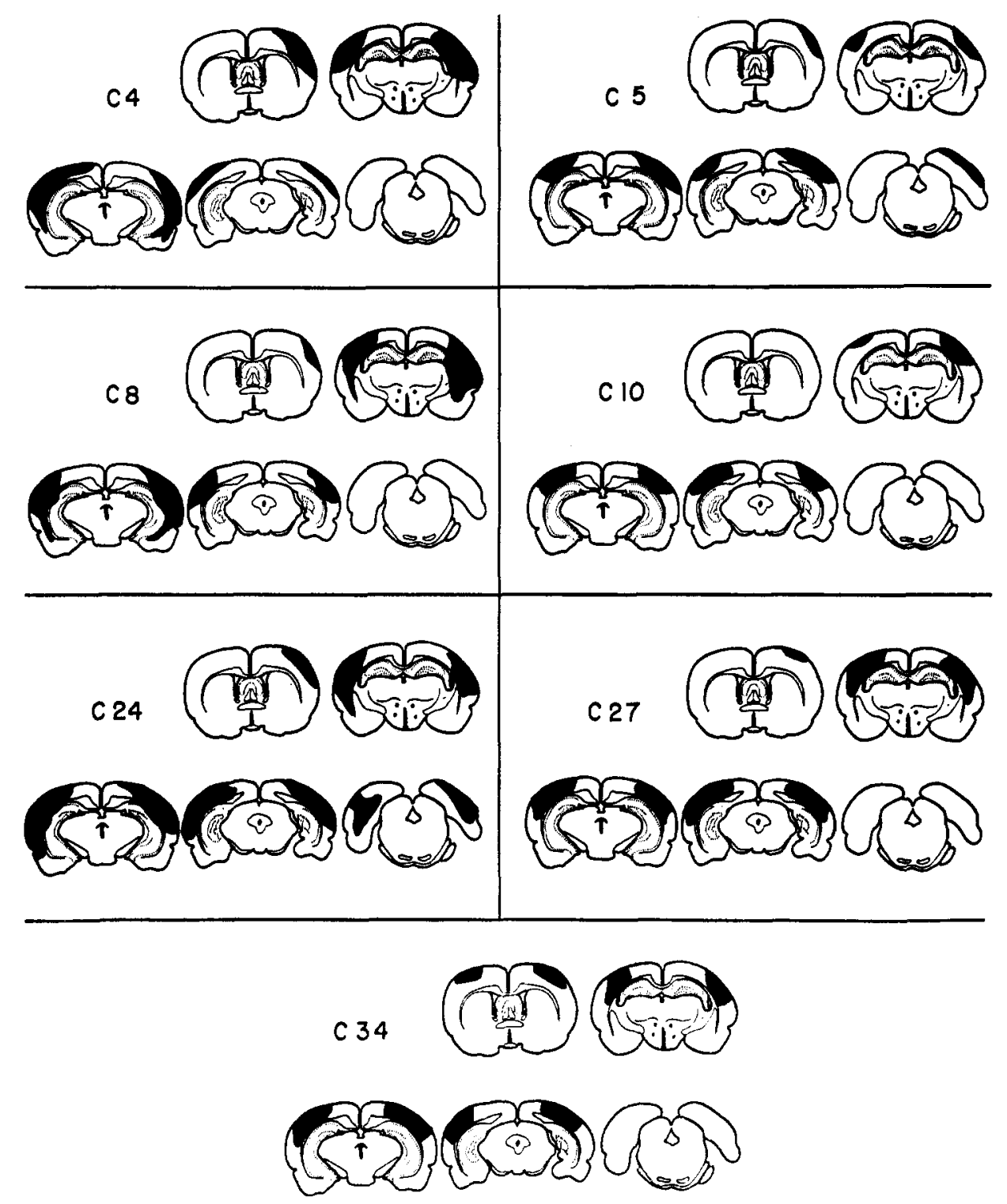

FIG. 2. Cross-sectional reconstructions of cortical lesions. Ablated tissue is indicated by solid dark areas.

procedures have been described in detail as they apply to the rat [12] and a similar technique has been used with the gerbil both in the present study and in a previous publication [8].

Histological. At the conclusion of the experiment, all lesioned gerbils were again anesthetized with pentobarbital, perfused with normal saline followed by $10 \%$ formalin and had their brains removed. These brains were embedded in paraffin, sectioned at $15 \mu$ thickness through the extent of the lesion, and the resultant sections were stained with thionin. The extent of injury in hippocampal and cortical lesion groups is depicted in Figs. 1 and 2. Histological examination of brain sections revealed considerable variation in the extent of hippocampal destruction, ranging from a minimum of approximately 25 per cent (H-29) to a maximum of approximately 95 per cent $(\mathrm{H}-32)$. The cortical lesions were generally restricted to the neocortex, although some minor injury to hippocampal tissue was observed.
Behavioral. The behavioral measurement procedures employed in the present study included: (a) time-sampling of individual and social activities in the home cage, (b) measurement of daily water consumption and the weight of cardboard shredded for nest-building purposes, (c) experimenter recorded observation of squares traversed and fecal elimination in a 10 min open field test, and (d) experimenter recorded contacts with novel stimulus objects introduced to the home cage.

During the week preceding surgery, each animal was observed during two 15 min test periods with visitor gerbils. A minimum of $24 \mathrm{hr}$ elapsed between such test periods. Interactions between the resident animals and the visitors were recorded using a time-sampling procedure during minutes $1-5$ and 11-15 following introduction of visitors in the central cage area of the resident animal.

After allowing 17 days for postoperative recovery, the 
following sequence of time-sampled observations was obtained: alone $(5 \mathrm{~min})$, alone $(5 \mathrm{~min})$, with visitor $(10 \mathrm{~min})$, with visitor $(10 \mathrm{~min})$. The visitor tests were conducted as previously described and actually involved a $15 \mathrm{~min}$ period of contact between visitor and resident gerbils. A minimum of $24 \mathrm{hr}$ elapsed between test periods; all time sampling tests were carried out between 3-5 p.m. Throughout the experiment the room was illuminated daily from 8 a.m. -6 p.m.

The basic time sampling procedure involved dividing each minute of observation into $12,5-\mathrm{sec}$, periods and recording the behavior observed in a given 5 sec period on a prepared scoring sheet. Behavior patterns were coded into 21 categories. Fifteen categories of behavior were individual patterns, i.e. they could occur without the presence of a visitor. However, several of these activities (foot-thumping and ventral rubbing) rarely occurred in the absence of a visitor and, in the context of the present study, are properly classified as socially elicited behavior patterns. The remaining 6 categories involved specific physical interaction with visitor gerbils. The individual patterns to be discussed include: locomotion, rearing, sniffing, grooming, sleeping/lying, alert inactivity (standing or freezing), burrowing and shredding of nest materials. Feeding, drinking, climbing on the beaker, jumping and nest construction activities (other than shredding of nest materials) did not occur with sufficient frequency during the limited periods of observation to warrant inclusion in the present report.

Categories of social reactivity included: locomoting toward or after the visitor, sniffing or grooming the visitor, standing side-by-side with the visitor, hostile encounters with the visitor (fighting or assumption of the upright boxing position), being sniffed or groomed by the visitor, locomoting away from the visitor, ventral rubbing and foot-thumping.

Some comment is in order regarding the shredding, ventral rubbing and foot-thumping categories as these patterns are not commonly observed in other laboratory animals. Shredding of nest materials, in this case pieces of thick cardboard, is a very frequent activity in the caged gerbil and is carried out in stereotyped fashion with the cardboard grasped between the forepaws. It appears in both male and female gerbils and is difficult to satiate [6]. Ventral-rubbing is a flattening of the abdominal surface against objects in the environment and is presumably a device for territorial marking. Gerbils possess a sebaceous gland in this region which is visible in the midline. Thiessen and his colleagues $[22,23]$ have demonstrated that both the gland pad and the stereotyped ventral-rubbing behavior are androgen dependent and are normally directed at elevated objects in the environment. We have further found that the frequency of occurrence of the pattern is markedly enhanced by the introduction of visitor gerbils (Glickman, Higgins and Morrison, unpublished observations) and that it is under dominantly olfactory control, although other sense modalities do contribute to its appearance [1]. Foot-thumping consists of a rapid drumming of the hindlegs against the floor of the cage. It evidently occurs in a variety of desert rodents [5] and has sometimes been supposed to have a signalling function toward conspecifics, although no direct evidence of this has ever been produced. In the gerbil, footthumping has been observed most vigorously during sexual encounters [15] and following or during electrical stimulation of the brain $[7,18]$, although a briefer foot-thumping reaction is also obtained following non-copulatory encounters with male or female visitor gerbils (Glickman, Higgins and Morrison, unpublished observations). At this time, it seems safest to characterize foot-thumping as occurring in a variety of situations which have as their common element the fcature of inducing excitement in the gerbil.

The 10 min test of open field activity and the 10 min test of reactivity to novel stimulus objects were carried out on successive days following the conclusion of the individual and social time-sampling observations. Gerbils were given a single exposure to the field in which all animals were gently deposited in a corner square from a $600 \mathrm{ml}$ beaker. The experimenter recorded the number of squares traversed; the placement of both forepaws across a line was the criterion for entry into a given square.

Reactivity to novel objects was examined through a procedure analogous to that originally developed by. Berlyne [2] and Welker [26], but employing a time-sampling technique similar to that which has previously been described. The response categories consisted of: object-manipulation, objectbiting, object-sniffing, ventral-rubbing of objects, carrying of objects and burying of objects. The dowel and the tubing were placed in the animals' home cage for a $10 \mathrm{~min}$ period. After $10 \mathrm{~min}$, the tubing was removed and the length of steel chain was substituted for the final $5 \mathrm{~min}$ of observation. Timesampled reactivity scores were obtained during min $1-5$ and $11-15$ of the test session.

Water intake was measured on each of the five days preceding surgery as well as Days 6-10 and 18-22 postoperatively. Measurements of the quantity of cardboard shredded for nest-building purposes were also obtained on these days by removing and weighing the unshredded remnants of the card placed in the cage on the previous day.

\section{RESULTS}

\section{Individual Behavior Patterns in the Home Cage}

Analysis of the time-sampled data obtained during the alone condition indicated a significant effect of brain lesions on locomotion, sniffing, rearing, and sleeping/lying activities (Table 1). When these were further analyzed with Duncan's range test, the gerbils with hippocampal lesions differed significantly $(p<0.05)$ from sham operated animals in all four response categories. They also differed significantly $(p<0.05)$ from the cortical lesion animals in regard to locomotion and

TABLE 1

Mean Time-Sampled Responses in the Home Cage: "ALONE" CONDITION

\begin{tabular}{lrrrr}
\hline & \multicolumn{3}{c}{ Lesion Group } & \\
\cline { 2 - 4 } \multicolumn{1}{c}{$\begin{array}{c}\text { Response } \\
\text { Categories }\end{array}$} & $\begin{array}{c}\text { Hippo- } \\
\text { campal }\end{array}$ & Cortical & $\begin{array}{c}\text { Sham } \\
\text { Operate }\end{array}$ & \multicolumn{1}{c}{$\begin{array}{c}\text { (F" Values } \\
(d f=2,20)\end{array}$} \\
\hline Locomotion & 29.1 & 12.1 & 4.0 & $6.69 \dagger$ \\
Sniffing & 21.6 & 5.3 & 8.9 & $4.00^{*}$ \\
Rearing & 27.9 & 19.9 & 4.7 & $5.44^{*}$ \\
Alert Inactivity & 31.8 & 41.3 & 20.0 & 0.73 \\
Grooming & 5.2 & 3.9 & 6.1 & 0.26 \\
Burrowing & 8.0 & 13.1 & 1.1 & 2.47 \\
Shredding & 9.0 & 21.6 & 19.6 & 0.59 \\
Sleeping/Lying & 6.7 & 10.6 & 47.4 & $7.40 \dagger$ \\
\hline
\end{tabular}

$* p<0.05$.

$\dagger p<0.01$. 
sniffing, but not in the quantity of rearing or sleeping/lying activity. Finally, the cortical lesioned group differed significantly $(p<0.01)$ from the sham operated group only in the quantity of sleeping/lying behavior.

The three behavior patterns facilitated by hippocampal lesions (locomoting, sniffing and rearing) were then analyzed in order to determine whether the increments resulted from perseveration of a particular activity (as indicated by a lengthened chain of successive $5 \mathrm{sec}$ periods in which the activity occurred), or whether the activity in question was initiated more frequently. The results of this analysis are presented in Table 2.

TABLE 2

Initiation and Duration of Selected Behavior Sequences

\begin{tabular}{lcccc}
\hline & \multicolumn{4}{c}{ Lesion Group } \\
\cline { 2 - 5 } & $\begin{array}{l}\text { Hippo- } \\
\text { campal }\end{array}$ & Cortical & $\begin{array}{c}\text { Sham "F" Values } \\
\text { Operate }\end{array}$ & $(d f=2,20)$ \\
\hline Mean frequency of & & & & \\
sequence initiation & & & & \\
$\quad$ Locomotion & 14.8 & 10.3 & 2.9 & $5.59^{*}$ \\
$\quad$ Sniffing & 12.3 & 3.7 & 4.7 & $5.30^{*}$ \\
$\begin{array}{l}\text { Rearing } \\
\text { Mean sequence }\end{array}$ & 10.7 & 10.1 & 3.3 & 3.36 \\
duration (consecutive & & & & \\
5 sec intervals) & & & & \\
$\quad$ Locomotion & 1.7 & 1.1 & 1.0 & 2.36 \\
Sniffing & 1.8 & 1.1 & 1.6 & 1.06 \\
Rearing & 3.2 & 1.7 & 1.0 & 1.36 \\
\hline
\end{tabular}

$* p<0.025$

In no case was a significant effect of the lesion on perseveration, so defined, obtained. However, there was a significant effect of the hippocampal lesion on the frequency of initiation of both locomotion and sniffing. Additional analysis with Duncan's range test revealed that the hippocampal animals initiated locomotor sequences more frequently than sham operate animals $(p<0.01)$ and initiated sniffing sequences more frequently than either cortical lesion $(p<0.01)$ or sham operate $(p<0.05)$ animals. The remaining differences were not statistically significant.

Grooming, burrowing, alert inactivity and shredding were not significantly affected by brain lesions as indicated by analysis of variance employing the time-sampled data. However, in the case of shredding, this is a somewhat misleading statistic. Preoperatively, all animals were shredding virtually their entire daily ration of carboard. By Days $18-22$ postoperatively, all animals in the sham operate and cortical lesion groups were again shredding 93-100 per cent of their daily allotment. However, 5 of the 9 hippocampal animals completely ceased shredding and only one of the 9 animals shredded at preoperative leveis. The extremely high scores generated by this one animal were sufficient to prevent achievement of a significant analysis of variance in the timesampled data; however, hippocampal lesions reduced the amount of shredding $/ 24 \mathrm{hr}$ from a preoperative value of $10.7 \mathrm{~g}$ to 0.7 and $2.7 \mathrm{~g}$ on postoperative Days $6-10$ and $18-22$, respectively ( $p<0.01$ ) for each of the postop.-preop. comparisons). Shredding was unaffected by the sham or cortical operations.

There was also an increment in daily water intake in the hippocampal lesion animals from a preoperative mean of $9.0 \mathrm{ml} /$ day to a mean postoperative value of $12.6 \mathrm{ml}$ on Days 18-22 $(p<0.025)$. Drinking was unaffected by operative procedures in the other two groups. This behavior appeared too infrequently during our time-sampling to permit an estimate of the extent to which this was a perseverative or frequency-of-initiation increment.

\section{Social Behavior in the Home Cage}

When a visitor gerbil is placed in the cage of a resident animal, a relatively stereotyped pattern of social interaction occurs. The resident gerbil immediately runs toward the visitor gerbil and follows the visitor about as the latter explores the environment into which he has been thrust. During this time, the resident attempts to sniff and groom the visitor. The visitor may passively permit this sniffing and grooming, or may attempt instead to sniff and groom the resident gerbil. This latter activity frequently escalates into aggressive behavior patterns indicated most clearly by assumption of the upright boxing posture, or a biting, kicking fight. These hostile activities are sometimes preceded or accompanied by assumption of the side-by-side position and occasionally terminated by flight of one of the contestants, although the latter may lead to further attack. Foot-thumping on the part of the resident gerbil may occur at any point in the encounter, but seems most probable during the early phases of the observation period. In contrast, ventral rubbing responses tend to appear in the latter portions of the 15 min test.

The quantitative aspects of reactivity to visitor gerbils are presented in Table 3. Since there are no observable lesion by sex of visitor interactions, reactions to male and female

TABLE 3

Home Cage Behavior: Reactivity to Visitor Gerbils Mean Time-Sampling Responses Per Category

\begin{tabular}{|c|c|c|c|c|c|c|}
\hline \multirow[b]{2}{*}{$\begin{array}{l}\text { Response } \\
\text { Categories }\end{array}$} & \multicolumn{6}{|c|}{ Lesion Groups } \\
\hline & $\begin{array}{l}\text { Hippo } \\
\text { Preop. }\end{array}$ & $\begin{array}{l}\text { campal } \\
\text { Postop. }\end{array}$ & $\begin{array}{l}\text { Cor } \\
\text { Preop. }\end{array}$ & $\begin{array}{l}\text { tical } \\
\text { Postop. }\end{array}$ & $\begin{array}{l}\text { Sham } \\
\text { Preop. }\end{array}$ & $\begin{array}{l}\text { Operate } \\
\text { Postop. }\end{array}$ \\
\hline $\begin{array}{l}\text { Running to visitor } \\
\text { Sniffand groom }\end{array}$ & 25.0 & 26.8 & 33.4 & $13.7 \dagger$ & 32.5 & 25.0 \\
\hline $\begin{array}{l}\text { visitor } \\
\text { "Side-by-side" }\end{array}$ & $\begin{array}{r}71.6 \\
8.6\end{array}$ & $\begin{array}{l}82.3 \\
1.6+\end{array}$ & $\begin{array}{l}83.6 \\
10.7\end{array}$ & $\begin{array}{c}60.3 \dagger \\
8.4\end{array}$ & $\begin{array}{r}97.0 \\
8.4\end{array}$ & $\begin{array}{c}70.0 \dagger \\
8.7\end{array}$ \\
\hline $\begin{array}{l}\text { Boxing and } \\
\text { fighting }\end{array}$ & 5.9 & $13.9 \dagger$ & 3.0 & $15.9 \dagger$ & 2.9 & 7.3 \\
\hline $\begin{array}{l}\text { Sniffed and } \\
\text { groomed by } \\
\text { visitor } \\
\text { Run from visitor } \\
\text { Ventral rubbing } \\
\text { Foot-thumping }\end{array}$ & $\begin{array}{r}8.7 \\
3.2 \\
8.9 \\
43.6\end{array}$ & $\begin{array}{r}11.0 \\
9.1 \\
5.2 \\
26.4\end{array}$ & $\begin{array}{r}10.9 \\
0.0 \\
5.1 \\
5.4\end{array}$ & $\begin{array}{c}9.9 \\
6.0 \dagger \\
6.3 \\
37.9+\end{array}$ & $\begin{array}{r}6.4 \\
5.1 \\
5.7 \\
16.9\end{array}$ & $\begin{array}{r}11.9 \\
6.3 \\
4.9 \\
28.7\end{array}$ \\
\hline
\end{tabular}

"Two hippocampal lesion animals, who obtained extremely high boxing and fighting scores preoperatively, were eliminated from analysis of this category in an effort to provide better preoperative matching between groups.

$\dagger p<0.05$ preop.-postop. difference, based upon the Wilcoxen Signed Rank Test for paired scores. 
visitors were combined in this table. The sham operate animals showed a significant preop.-postop. shift on but a single dimension of social interaction: a reduction in sniffing and grooming responses directed at visitor gerbils. The cortical lesion animals generally acted to avoid contact with visitor gerbils; rarely approaching an intruder, fleeing when approached, and exhibiting a decrement in sniffing-grooming of visitors similar to that of the sham operate animals. Aggressive contacts initiated by visitor gerbils resulted in an increment in hostile interactions following the cortical lesions. Finally, these animals seemed highly excitable and exhibited a marked increment in foot-thumping during the social reactivity tests.

Hippocampal lesion animals showed an increment in hostile encounters and a decrement in adoption of the motionless side-by-side position. The remaining patterns of social reactivity were unaffected by the hippocampal lesions, although interpretation of the foot-thumping data must be qualified by an extreme mismatch in preoperative scores between hippocampal and control groups. Territorial marking (ventral rubbing) was apparently unaffected by any of our lesion procedures.

\section{Investigatory Behavior}

The patterns of reactivity in the open field displayed by the three experimental groups are depicted in Fig. 3. A two-way analysis of variance revealed significant effects of lesions

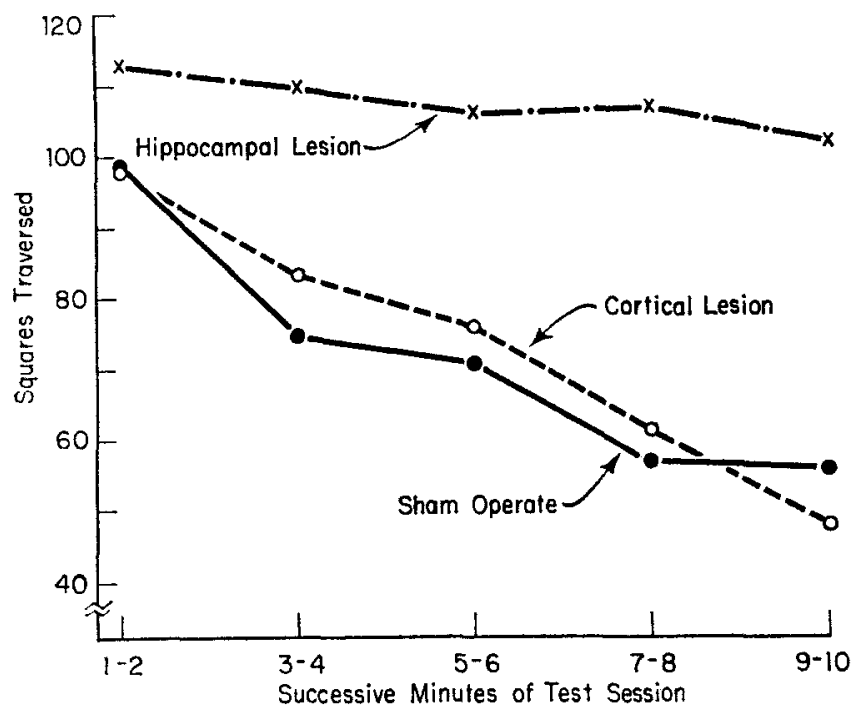

FIG. 3. Locomotor activity in the open field as a function of time in the test situation.

$(\mathrm{F}=8.79, d f=2,20, p<0.005)$ and time within session ( $\mathrm{F}=23.22, d f=4,80, p<0.001$ ), as well as a significant interaction between lesion group and the time-within-session variable. Further analysis with Duncan's range test, indicated that the hippocampal lesion animals were more active than either the cortical lesion or sham operate animals $(p<0.01)$, although the latter two groups did not differ significantly from each other. In addition, $F$ tests for within session locomotor changes substantiated the hypothesis that the significant time $\times$ lesion group interaction was due to the failure of the hippocampal lesion animals to habituate to the field between minutes $1-2$ and minutes $9-10(F=0.94, d f=$ $4,80, p>0.25)$. Both the cortical and sham operate groups demonstrated highly significant decrements during this period $(p<0.001)$. The defecation patterns in the field were apparently dissociated from the effects on locomotor activity, i.e. the sham operate animals deposited more fecal boli in the field (Mean $=12.0$ ) than either the cortical lesioned group $($ Mean $=5.7)$ or the hippocampal lesion group $($ Mean $=4.7$ ). A significant " $F$ " value $(3.80, d f=2,20, p=0.05)$ was supplemented by Duncan's range test which revealed that although both the cortical and hippocampal lesion groups differed from the sham operate group $(p-0.05)$, the two lesion groups did not differ significantly from one another.

In contrast to the increment in open field locomotor activity, the responses to novel stimulus objects introduced to their home cages were either depressed or unaffected by hippocampal lesions. The essential data are summarized in Table 4. Brain lesions produced significant shifts in manipu-

TABLE 4

Rfactivity to Novel Objects: Mean Responsfes Per 10 Minutes of Observation

\begin{tabular}{lrrrr}
\hline & \multicolumn{4}{c}{ Lesion Group } \\
\cline { 2 - 4 } \multicolumn{1}{c}{$\begin{array}{c}\text { Response } \\
\text { Categories }\end{array}$} & $\begin{array}{l}\text { Hippo- } \\
\text { campal }\end{array}$ & Cortical & $\begin{array}{c}\text { Sham } \\
\text { Operate }\end{array}$ & "F" Values \\
& & & & \\
\hline & & & & \\
\hline Biting & 25.6 & 42.9 & 43.0 & $7.56 \ddagger$ \\
Manipulating & 13.8 & 37.7 & 22.9 & $4.29 \dagger$ \\
Sniffing & 15.3 & 16.4 & 15.7 & 0.15 \\
Ventral Rubbing & 2.7 & 1.3 & 0.6 & 2.48 \\
Total* & 58.3 & 99.7 & 83.7 & $3.71 \dagger$ \\
\hline
\end{tabular}

*The total column includes several responses (carrying, pushing objects) which did not occur with sufficient frequency to permit individual statistical analysis.

$\dagger p<0.05$.

$\ddagger p<0.01$.

latory and biting responses directed at the objects, as well as in total reactivity to the objects. Sniffing objects and ventral rubs directed at objects were not affected by the lesions. Duncan's range test indicated that the hippocampal lesion animals exhibited significantly less total reactivity and less manipulation of the objects than the cortically lesioned animals $(p<0.05)$. They also demonstrated significantly less biting of the objects than either the cortical lesion animals or the sham operate animals $(p<0.05)$. The remaining comparisons did not achieve statistical significance.

\section{DISCUSSION}

Insofar as comparable data exist, the major findings regarding hippocampal lesion effects obtained in the present study correspond quite well with information from prior investigations in the rat. The increments in open field activity and water intake observed in the gerbil parallel similar results in the rat $[12,13,16,17,22]$, as do the increments in locomotion, rearing, and sniffing in the home cage [9]. Moreover, the decrement in sleeping/lying behavior is in accord with the previous 
report of Jarrard [9] and the disruption of nest-material shredding may be related to the interference with nest construction activities observed by Kim [11]. The decrement in reactivity to novel stimulus objects found in the present study has not previously been examined in the rat, but should temper any generalizations regarding hippocampal lesion effects on exploratory behavior. The enhancement of locomotion in a novel environment following hippocampectomy is probably most reasonably viewed as indicative of a responsespecific increment, rather than as a general potentiation of curiosity. In the latter regard, it is of interest that Jarrard and Bunnell [10] did not observe the open field activity increment in hippocampally lesioned hamsters. In addition, hamsters generally exhibited an enhancement of submissive social behavior following hippocampal lesions [3]. Both of these observations in hamsters contrast with the results of the present study, although it is not yet clear whether we are confronted with a true species difference or a more subtle procedural discrepancy.

The results of the present study emphasize the diversity of hippocampal lesion effects on species-characteristic behavior patterns in the Mongolian gerbil. While certain behavior sequences increase in frequency, others either decrease or are unaffected by the lesion. Any comprehensive theory of hippocampal function should ultimately account for the entire pattern of behavioral modification and not just those sequences which are selectively enhanced. It is possible to argue that those patterns which are enhanced are the prepotent ones in the situation and that the others are simply suffering a secondary reduction. However, some activities which normally occur with relatively high frequency, e.g. shredding and sleeping/lying, are reduced rather than enhanced by a hippocampal lesion. Although it is easier to visualize the depression of the latter activities as a consequence of increments in locomotion, rearing and sniffing, it is also possible that these increments are in some way related to sleep deprivation resulting from the lesion.

Our failure to find direct evidence of a perseveration effect can probably be attributed to the crudity of our time-sampling procedure, which measures in $5 \mathrm{sec}$ units rather than providing a direct index of elapsed time. Nevertheless, there is clear evidence that lesion-induced increments in locomotion and sniffing result, to a large extent, from shifts in the frequency of initiating activities. This argues against a simple responseperseveration view of the hippocampal lesion effect. Rather, as Douglas [4] has observed, such shifts could be explained in terms of some kind of sensory gating mechanism which results in hippocampectomized animals overreacting to some stimuli [8] and underreacting to others [16, 17, 27]. This could also be compatible with the elevated non-decremental response to the open field situation and with the relatively reduced response to novel stimulus objects observed in the present study. The problem would then shift to determination of the critical stimulus dimensions which selectively enhance or depress reactivity in hippocampally lesioned animals.

Finally, a provocative correlation apparently exists between hippocampal lesion effects on behavior patterns in home cage or novel situations and electrical recording data involving similar tests in both gerbils and rats. Hippocampal theta activity has been found to accompany sniffing, rearing and some aspects of locomotor activity in gerbils [14] and rats $[18,25]$, although Vanderwolf $[25]$ indicates that vibrissae movements per se are not correlated with rhythmic slow activity in the hippocampus. Alternately, hippocampal desynchronization is the prime accompaniment of tense inactivity and a variety of highly stereotyped automatic behavior patterns including grooming, eating, drinking and in the gerbil, foot-thumping. In both the Jarrard study [9] and the present experiment, hippocampal lesions were found to enhance the class of sniffing, rearing and locomotor activities, while tense inactivity, grooming and a variety of additional highly stereotyped activities were either unaffected or depressed. In general, those behavior patterns accompanied by hippocampal theta have been facilitated by hippocampal lesions while those patterns correlated with hippocampal desynchronization are not so affected. The appearance of sniffing, as indicated by isolated vibrissae movements [25] during desynchronized hippocampal records, and the enhanced water intake which sometimes follows hippocampal lesions, would seem to be the principle exceptions to the preceding generalization. However, the former discrepancy may be due to different definitions of sniffing employed in the experiments cited, while the latter effect may be mediated either by an anatomically distinct region of the hippocampus, or a separable hormonal mechanism.

\section{REFERENCES}

1. Baran, D. and S. E. Glickman. "Territorial marking" in the Mongolian gerbil: A study of sensory control and function. J. comp. physiol. Psychol. In press.

2. Berlyne, D. E. Novelty and curiosity as determinants of exploratory behavior. Br. J. Psychol. 41: 68-80, 1950.

3. Bunnell, B. N., E. E. Burkett and L. E. Jarrard. Hippocampal lesions and social behavior in the golden hamster. Paper presented at the annual meeting of the Midwestern Psychological Association, Chicago, 1967.

4. Douglas, R. J. The hippocampus and behavior. Psychol. Bull. 67: 416-442, 1967.

5. Eisenberg, J. The behavior of hetereomyid rodents. Univ. Calif. Publ. Zool. 69: 1-100, 1963.

6. Glickman, S. E., L. Fried and B. A. Morrison. Shredding of nesting material in the Mongolian gerbil. Percept. Mot. Skills 24: 473-474, 1967.
7. Glickman, S. E. and T. J. Higgins. Elicited behavior and re inforcement in the Mongolian gerbil. In: Environment Modification of Brain-stimulation Effects. B. Beer (Chairman). Symposium presented at the annual meeting of the Eastern Psychological Association, Washington, D.C., 1968.

8. Ireland, L. C. and R. L. Isaacson. Reactivity in the hippocampectomized gerbil. Psychonom. Sci. 12: 163-164, 1968.

9. Jarrard, L. E. Behavior of hippocampal lesioned rats in home cage and novel situations. Physiol. Behav. 3: 65-70, 1968.

10. Jarrard, L. E. and B. N. Bunnell. Open-field behavior of hippocampal-lesioned rats and hamsters. J. comp. physiol. Psychol. 66: 500-502, 1968.

11. Kim, C. Nest-building, general activity and salt preference of rats following hippocampal ablation. J. comp. physiol. Psychol. 53: 11-16, 1960.

12. Kimble, D. P. The effects of bilateral hippocampal lesions in rats. J. comp. physiol. Psychol. 56: 273-283, 1963. 
13. Kimble, D. P. and G. D. Coover. Effects of hippocampal lesions on food and water consumption in rats. Psychonom. Sci. 4: 91-92, 1966.

14. Kramis, R. C. and A. Routtenberg. Rewarding brain stimulation, hippocampal activity and footstomping in the gerbil. Physiol. Behav. 4: 7-11, 1969.

15. Kuehn, R. and I. Zucker. Reproductive behavior of the Mongolian gerbil (Meriones unguiculatus). J. comp. physiol. Psychol. 66: $747-752,1968$.

16. Leaton, R. N. Exploratory behavior in rats with hippocampal lesions. J. comp. physiol. Psychol. 59: 325-330, 1965.

17. Roberts, W. W., W. N. Dember and M. Brodwick. Alternation and exploration in rats with hippocampal lesions. $J$. comp. physiol. Psychol. 55: 695-700, 1962.

18. Routtenberg, A. Hippocampal correlates of consummatory and observed behavior. Physiol. Behav. 3: 533-535, 1968.

19. Routtenberg, A. and R. C. Kramis. "Foot-stomping" in the gerbil: Rewarding brain stimulation, sexual behavior and foot shock. Nature 214: 173-174, 1967.

20. Schwentker, V. The Gerbil: An Annotated Bibliography Available from Tumblebrook Farm, Inc., Brant Lake, New York, 1968.
21. Tanimoto, K. An ecological report on several plague-carrying animals in northeast China: 3. J. Zool. 55: 117-128, 1943. (Translated from the Japanese original.)

22. Teitelbaum, H. and P. Milner. Activity changes following partial hippocampal lesions in rats. J. comp. physiol. Psychol 56: 284-289, 1963.

23. Thiessen, D. D. The roots of territorial marking in the Mongolian gerbil: A problem in species-common topography Behav. Res, Meth. Instrum. 1: 70-76, 1968.

24. Thiessen, D. D., H. C. Friend and G. Lindzey. Androgen control of territorial marking in the Mongolian gerbil. Science 160: $432-434,1968$.

25. Vanderwolf, C. H. Hippocampal electrical activity and voluntary movement in the rat. Electroenceph. clim. Neurophysiot 26: 407-418, 1969.

26. Welker, W. I. Some determinants of play and exploration in chimpanzees. J. comp. physiol. Psychol. 49: 84-89, 1956.

27. Wickelgren, W. O. and R. L. Isaacson. Effect of the introduction of an irrelevant stimulus on runway performance of the hippocampectomized rat. Natture 200: 48-50, 1963. 